\title{
Combination of modified Sugiura technique and proximal splenorenal shunt for the management of portal vein thrombosis in noncirrhotic portal hypertension
}

This article was published in the following Dove Press journal:

Clinical and Experimental Gastroenterology

\author{
Hendry Irawan' \\ I Made Mulyawan ${ }^{2}$
}

'General Surgery Department, Faculty of Medicine Udayana University, Sanglah General Hospital, Denpasar, Bali, Indonesia; ${ }^{2}$ Digestive Surgery Division, General Surgery Department, Faculty of Medicine Udayana University, Sanglah General Hospital, Denpasar, Bali, Indonesia
Correspondence: Hendry Irawan General Surgery Department, Faculty of Medicine, Udayana University, Sanglah General Hospital, Jl. Diponegoro,

Denpasar, Bali, 80113, Indonesia

Tel +62 821 25097786

Email hendry_irawan@rocketmail.com
Background: Noncirrhotic portal hypertension $(\mathrm{NCPH})$ is a condition when a high hepatic venous pressure gradient with preserved liver functions and the absence of parenchymal dysfunction. NCPH with portal vein thrombosis (PVT) is a rare condition. Surgery aims to reduce portal vein flow and alter portal vein circulation.

Case: A male, 59 years old, complained of blackish stool in the last 2 weeks and enlarged abdomen. Physical examination revealed anemia and melena with splenomegaly and ascites. Laboratory findings were anemia, normal hepatobiliary function, and no liver infection. Abdominal Doppler ultrasonography and contrast-enhanced abdominal computed tomography scan revealed ascites, splenomegaly, noncirrhotic liver, dilatation of portal vein, low portal vein peak velocity, and PVT. Esophagogastroduodenoscopy revealed esophageal varices grade 3 with a positive red color sign and cardia stomach varices. We performed a modified Sugiura technique through the left subcostal incision and proximal splenorenal shunt. The procedures of the modified Sugiura technique are splenectomy, devascularization, transection, and end-to-end anastomosis of the lower esophagus above the gastroesophageal junction, devascularization of the upper $2 / 3$ of the lesser and greater curvatures of the stomach, and pyloroplasty. Portal circulation alteration used the proximal splenorenal shunt with end-to-side anastomosis of the splenic vein to left renal vein. At the one-year follow-up after surgery, his physical condition was better and there was no sign of complications.

Conclusion: Devascularization procedure using a modified Sugiura technique is useful to treat and avoid rupture of esophageal varices. Portal circulation alteration using the proximal splenorenal shunt is a good choice. The treatment in NCPH utilizing the combination of modified Sugiura technique and the proximal splenorenal shunt is proper without complication.

Keywords: modified Sugiura technique, proximal splenorenal shunt, portal vein thrombosis, noncirrhotic portal hypertension

\section{Introduction}

Noncirrhotic portal hypertension ( $\mathrm{NCPH}$ ) is a condition when a high hepatic venous pressure gradient (HVPG) with preserved liver functions and the absence of parenchymal dysfunction. ${ }^{1,2}$ Based on anatomy, etiology of NCPH can be divided into pre-hepatic, hepatic, and post-hepatic, by increasing resistance to blood flow. ${ }^{1,2}$ One of the conditions of pre-hepatic NCPH is portal vein thrombosis (PVT), it is 
leading decrease portal vein flow and increase resistance. ${ }^{1-}$

${ }^{4}$ In the developed country, the second cause of portal hypertension after cirrhosis is PVT, but it must be distinguished between cirrhotic or noncirrhotic PVT. ${ }^{3}$

Portal vein obstruction in cirrhosis patient is associated with hepatocellular carcinoma and invasion of a primary tumor causes the blockage. ${ }^{3,4}$ PVT causes portal hypertension in the western country, approximately $5-10 \%$ cases, but in the developing country, $35-40 \%$ cases portal hypertension are associated to PVT. ${ }^{5}$ But it is a rare condition when PVT in the noncirrhotic patient. ${ }^{3,4}$ About one-third of patients' etiology is unknown ${ }^{3}$ and portal vein obstruction is usually well tolerated and often asymptomatic. ${ }^{5}$

In the noncirrhosis condition, the liver activity is regular and absence of parenchymal dysfunction. High portal pressure can develop into life-threatening complications such as variceal bleeding, intestinal venous occlusion or ischemia, and ascites. ${ }^{3,4}$ Gastroesophageal varices may occur in early PVT in NCPH, another condition such as portal hypertensive gastropathy is rare. Ascites may occur, and it is associated with gastrointestinal bleeding and infection. ${ }^{4}$

Treatment in NCPH is to reduce portal pressure and to impede variceal bleeding. ${ }^{2,6,7}$ The goal of surgery in $\mathrm{NCPH}$ patient is to minimize portal vein resistance by devascularization of esophageal varices and creating a portosystemic shunt. ${ }^{6-8}$ The operation can do if patients with portal hypertension get the complication, no response to pharmacologic and endoscopic management. However, surgery can be indicated in recurrent bleeding or infection, restriction of activities of daily living, inadequate health care facility or want to do a definitive one-time treatment. ${ }^{2,5,6}$

We reported a patient with a chief complaint was the blackish stool and after examination, we found PVT in NCPH. We performed the combination of modified Sugiura technique and proximal splenorenal shunt. His condition recovered well without any complications after surgery. He can do daily activities and take medicine to prevent portal hypertension.

Written informed consent for publication of the case details and images has been provided by the patient. A case report publication does not require approval from the Faculty of Medicine Udayana University and Sanglah General Hospital Review Board.

\section{Case report}

A male, 59 years old, complained blackish stool in the last 2 weeks. His abdomen had slowly enlarged over the previous 4 years, and he felt pain especially in the middle of the stomach. He denied consuming alcohol drink, smoking, or history of other diseases, such as hepatitis and congenital disorder of the blood. The patient's condition gets weaker, but he can still eat and drink, and no vomiting. There is no swelling in the extremities.

Physical examination revealed pale of the eyelid, no icteric, no hepatomegaly, splenomegaly, and ascites. Rectal examination was positive of blackish stool, no fresh blood, and no palpable mass. Laboratory finding was anemia (hemoglobin $6.88 \mathrm{~g} / \mathrm{dL}$ and haematocrit 22.02\%), normal leukocyte and thrombocyte, hypoalbuminemia (albumin $2.8 \mathrm{~g} / \mathrm{dL}$ ), normal liver function (AST 14.7 U/L and ALT 11.1 U/L), and normal renal function (BUN $22.8 \mathrm{mg} / \mathrm{dL}$ and serum creatinine $0.79 \mathrm{mg} / \mathrm{dL}$ ). Hemostatic test slightly elevated with APTT $30.9 \mathrm{~s}$, PPT $16.7 \mathrm{~s}$, and INR 1.43. We also found nonreactive at $\mathrm{HBsAg}$ and anti-HCV test, normal bilirubin serum (total $0.78 \mathrm{mg} / \mathrm{dL}$, direct $0.31 \mathrm{mg} / \mathrm{dL}$, and indirect $0.47 \mathrm{mg} / \mathrm{dL})$, normal alkaline phosphatase (60 U/L), and normal gamma-GT ( $39 \mathrm{U} / \mathrm{L}$ ), but high CRP count $23.39 \mathrm{mg} / \mathrm{L}$ (normal $0-5 \mathrm{mg} / \mathrm{L}$ ).

The abdominal Doppler ultrasonography presented non cirrhotic liver with average size $(13 \mathrm{~cm})$, splenomegaly $(13.9 \mathrm{~cm})$, dilatation of portal vein $(1.27 \mathrm{~cm})$, low portal vein peak velocity $(19.4 \mathrm{~cm} / \mathrm{s})$, and ascites (Figure 1). This finding was confirmed with contrast-enhanced abdominal computed tomography (CT) scan, which revealed dilatation of portal vein with thrombus, normal liver parenchymal, normal biliary tract, splenomegaly with dilatation of splenic vein, and ascites (Figure 2). He was examined used esophagogastroduodenoscopy, which revealed esophageal varices grade 3 with the positive red color sign and stomach varices (Figure 3).

We transfused packed red cell two bags each day to improve hemoglobin level, but it cannot achieve until hemoglobin level was $10 \mathrm{~g} / \mathrm{dL}$. Every day he got melena, so it is indicated ongoing upper gastrointestinal bleeding. We decided to do Sugiura technique surgery ${ }^{8}$ with his baseline hemoglobin $5.29 \mathrm{~g} / \mathrm{dL}$. We performed the modified Sugiura technique through left subcostal incision (Figure 4A) and proximal splenorenal shunt.

We performed splenectomy first (Figure 4B) followed by devascularization of the distal esophagus using harmonic scalpel through hiatus of diaphragm. We made a small anterior gastrostomy. Then, we made a transection and end-to-end anastomosis of the lower esophagus (Figure 4C) using a CDH29A stapling device (Ethicon curved intraluminal stapler). We performed separate Lembert suture to reinforce of the esophageal anastomosis and stitched the gastrostomy. We performed devascularization of the upper $2 / 3$ of the lesser and major gastric curvature 

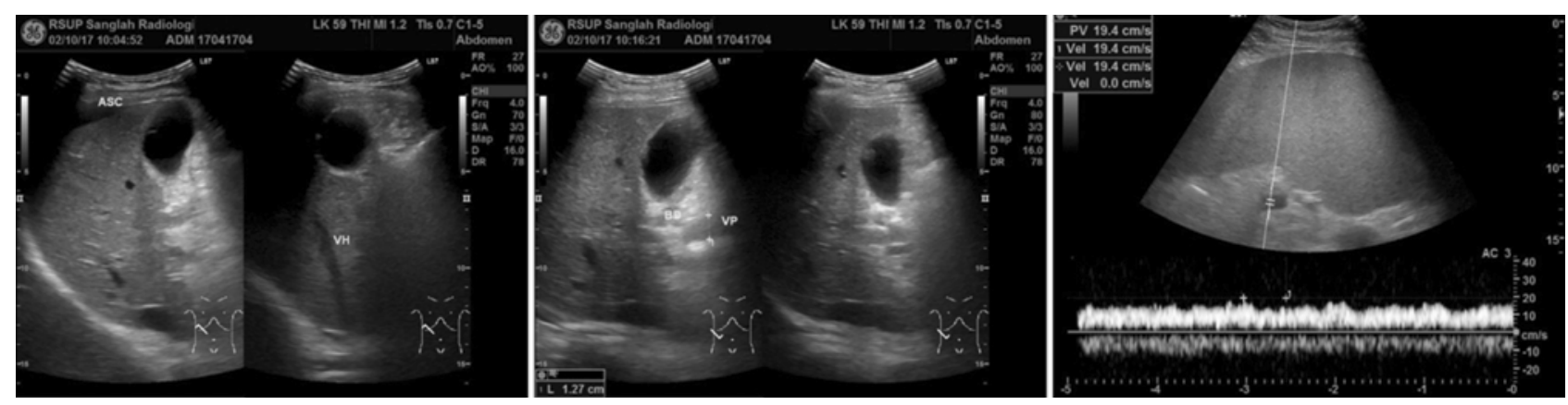

Figure I Abdominal Doppler ultrasonography with ascites, dilatation of portal vein, and low portal vein peak velocity.
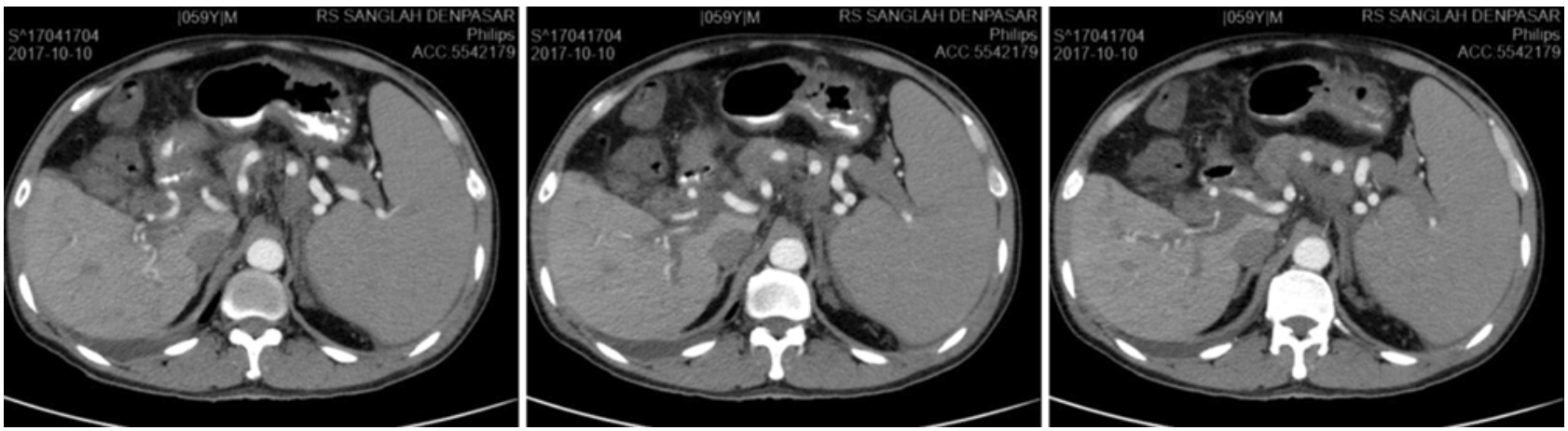

Figure 2 Contrast-enhanced abdominal CT scan with dilatation of portal vein with thrombus and dilatation of splenic vein.
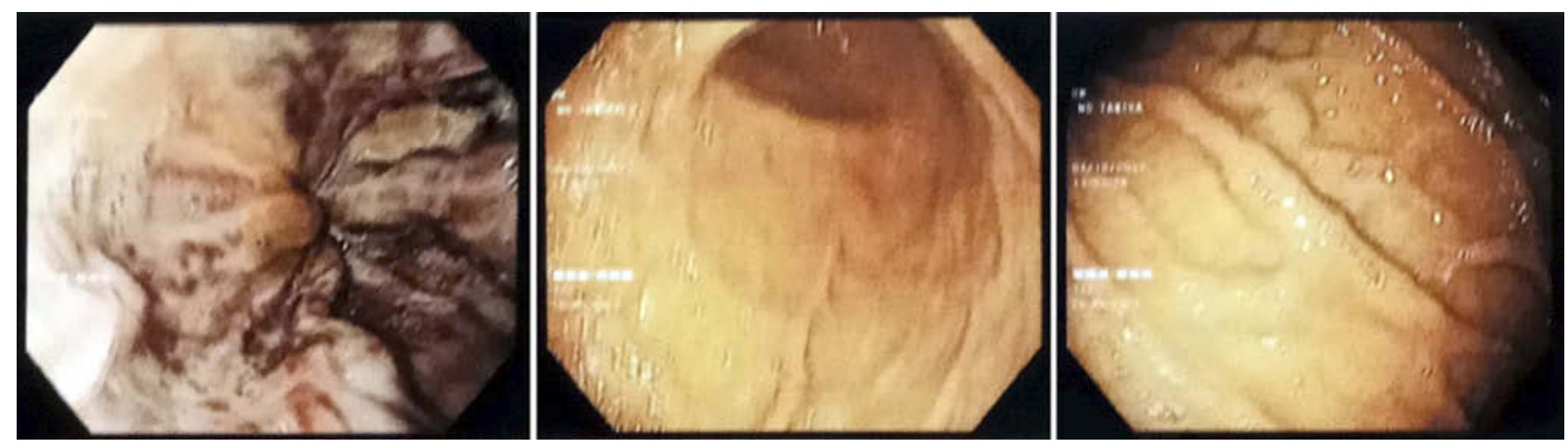

Figure 3 Esophagogastroduodenoscopy, esophageal varices grade 3 with the positive red color sign (left), esophagogastric junction (middle), and cardia stomach varices (right).

(Figure 4D) and then pyloroplasty to facilitate gastric emptying (Figure 4E). The last procedure we anastomosed end-to-side of the splenic vein to left renal vein (Figure 4F).

His condition improved after surgery and overwhelming post-splenectomy infection (OPSI) did not occur. He can eat and normally drink, no pale, no fatigue, and no melena. He consumed medicine propranolol $60 \mathrm{mg}$ per day to prevent portal hypertension and warfarin $5 \mathrm{mg}$ per day to release the thrombus. Two months after surgery, we examined esophagogastroduodenoscopy and revealed esophageal varices grade 2 with the negative red color sign, cardia stomach edema, no gastric varices, and gastric snakeskin (Figure 5). We evaluated esophagogastroduodenoscopy 6 months after surgery, the results were the same as the previous examination, but there was no edema in the gaster. One-year follow-up after surgery, his physical condition was better and no sign of complications.

\section{Discussion}

$\mathrm{NCPH}$ is a wide range of vascular condition leading to portal hypertension, and it classified anatomically by the site of 

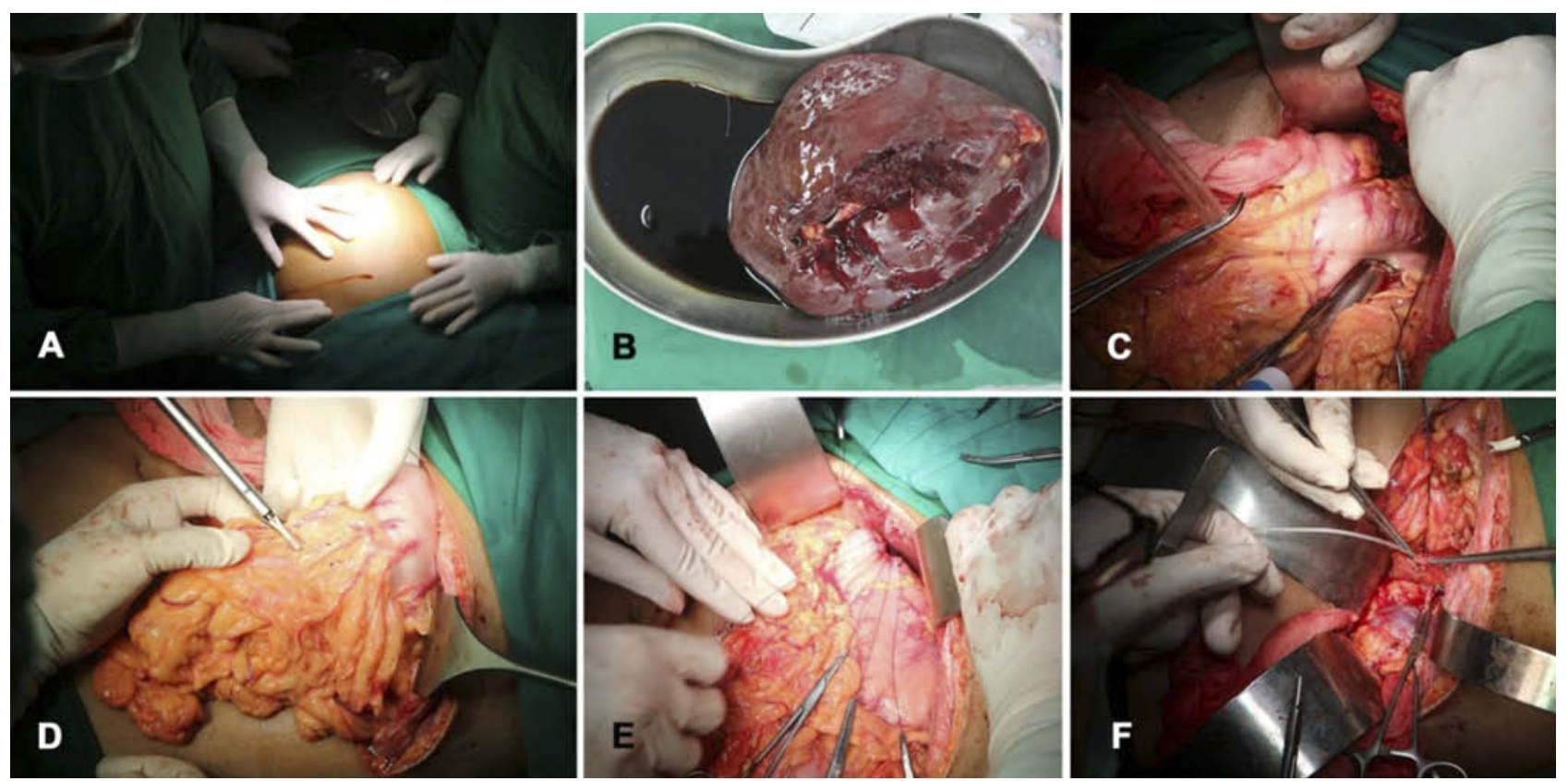

Figure 4 Step by step the operation. Left subcostal incision (A); splenectomy (B); transection and end-to-end anastomosis of the lower esophagus (C); devascularization of the upper $2 / 3$ of the major gastric curvature (D); pyloroplasty $(\mathbf{E})$; proximal splenorenal shunt $(\mathbf{F})$.
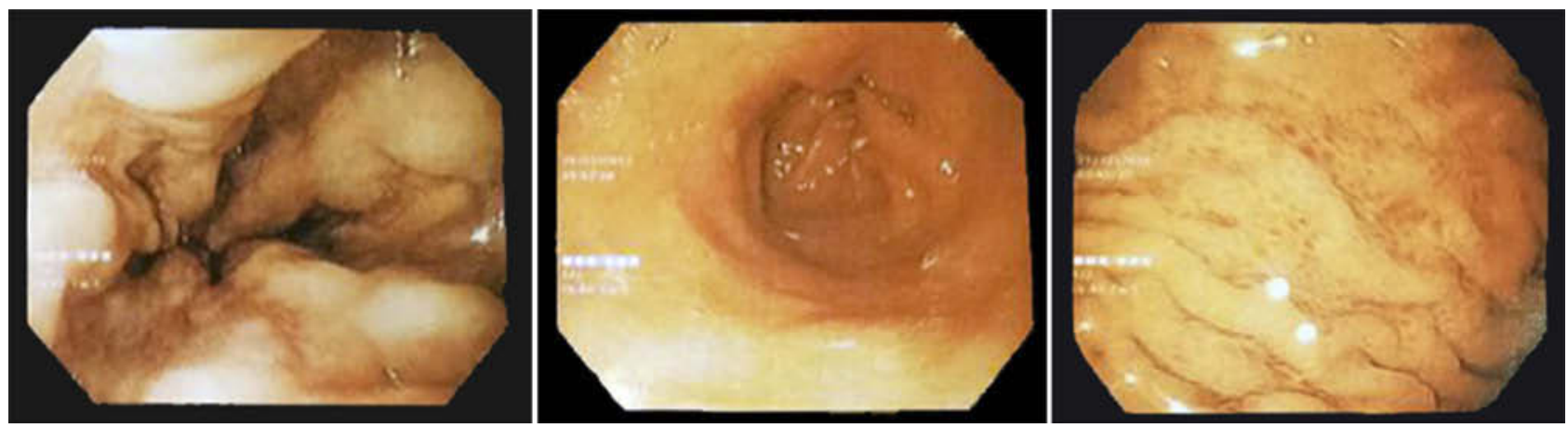

Figure 5 Esophagogastroduodenoscopy 2 months after surgery, esophageal varices grade 2 with the negative red color sign (left), cardia stomach edema (middle), and gastric snakeskin (right).

resistance to blood flow. ${ }^{1,2}$ Patients with NCPH have proper liver function and normal liver parenchyma. ${ }^{1-4}$ Classification and causes of NCPH are shown in Table $1 .{ }^{5}$ PVT can occur $6-11 \%$ in cirrhotic patients, ${ }^{9}$ but it is a rare finding in non cirrhotic patient. $^{3,4,9}$

PVT is one of cause extrahepatic portal vein occlusion. ${ }^{3}$ The occlusion of the portal vein can increase venous pressure gradient. ${ }^{1-4}$ The conditions that can be risk factors for PVT are blood clotting disorders, peritonitis or intra-abdominal infection, and portal vein anomaly (stenosis or atresia). ${ }^{5}$

Clinical presentation of PVT divided into acute or chronic thrombosis. ${ }^{4,5}$ The main complaints in acute PVT are the abdominal or lumbar pain, intestinal ischemia or dysfunction, fever, metabolic acidosis, ascites, rectal bleeding, diarrhea, and sepsis. ${ }^{4,5}$ In chronic PVT, it can be asymptomatic or characterized by splenomegaly, pancytopenia, varices, and ascites. ${ }^{5}$ Gastroesophageal varices may develop early stage, later it frequently causes variceal bleeding. Portal hypertensive gastropathy, ascites, and encephalopathy are a rare condition. ${ }^{4}$ Anemia and splenomegaly are common in extrahepatic portal vein obstruction. ${ }^{5}$

Radiological investigations use abdominal Doppler ultrasonography, abdominal CT scan, and magnetic resonance angiography to assess portal vein patency, portal cavernoma, the structure of a hepatobiliary system, splenomegaly, and evaluation another anomaly. ${ }^{3-5}$ Liver cirrhosis was confirmed by clinical, laboratory, or imaging findings. In noncirrhotic patients, liver function test was standard. ${ }^{3,4}$ Liver biopsy is not mandatory ${ }^{5}$ to proven 
Table I Classification of noncirrhotic portal hypertension ${ }^{1,5}$

\begin{tabular}{|c|c|}
\hline & re-hepatic \\
\hline & $\begin{array}{l}\text { Extrahepatic portal vein obstruction (portal vein thrombosis) } \\
\text { Splenic vein thrombosis } \\
\text { Splanchnic arteriovenous fistula } \\
\text { Splenomegaly due to any cause }\end{array}$ \\
\hline & Jepatic \\
\hline & 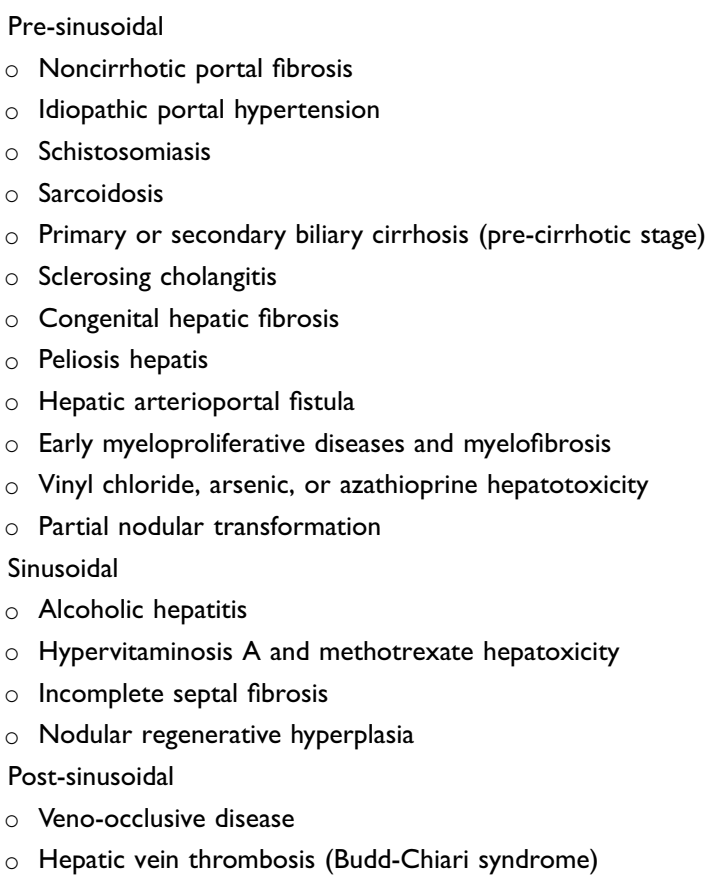 \\
\hline & ost-hepatic \\
\hline & $\begin{array}{l}\text { Inferior vena cava web } \\
\text { Constrictive pericarditis and restrictive cardiomyopathy } \\
\text { Tricuspid regurgitation } \\
\text { Severe right-sided heart failure }\end{array}$ \\
\hline
\end{tabular}

cirrhosis, but it is better to confirm NCPH with normal liver biopsy. Other modality used endoscopy in extrahepatic portal vein obstruction, to evaluate esophageal, gastric, and anorectal varices. ${ }^{5}$

Treatments of acute PVT are to release thrombosed vein, to avoid intestinal infarction, and correct any underlying disease. ${ }^{4}$ Anticoagulation therapy can recanalize partial and complete the thrombosed vein, $40-50 \%$, respectively. ${ }^{4}$ Turnes et al's study showed $44 \%$ recanalization in patients who get anticoagulation therapy within 30 days of the onset of symptoms, compared to noanticoagulation group $(p=0.008) .{ }^{10}$ Using early anticoagulation therapy was significantly increased recanalization to $60 \%$ of patients. They consumed anticoagulation drug within the first week after the diagnosis and only $20 \%$ recanalization if used later. ${ }^{4,10}$ Kobilica et al's study found early anticoagulation therapy after diagnosed PVT had 58\% complete recanalization, $29 \%$ partial recanalization, and $13 \%$ failed within first 30 days therapy. ${ }^{3}$ Using early anticoagulation therapy for 6 months gives a good outcome. ${ }^{4,10}$

Chronic PVT leads to portal hypertension and complications, such as variceal bleeding. ${ }^{3,4}$ Anticoagulation therapy can avoid the development and relapse of thrombosis without elevating the gastrointestinal bleeding. ${ }^{4}$ Treatment of variceal bleeding in the patient with $\mathrm{NCPH}$ can use endoscopic ligation or beta-blocker drug such as propranolol. ${ }^{4,5}$ Acute variceal bleeding is excellent using endoscopic therapy. ${ }^{5}$ A study showed that endoscopic variceal ligation was not better than consuming propranolol for protection rebleeding in patients with $\mathrm{NCPH}^{4}$

Treatment in NCPH is to reduce portal pressure and to avoid complications such as variceal bleeding. ${ }^{2,6,7}$ Surgery is indicated if endoscopic therapy cannot control bleeding or other indication such as massive splenomegaly, portal biliopathy, rare blood group, recurrent bleeding or infection, restriction of activities of daily living, inadequate health care facility or want to do a definitive one-time treatment. ${ }^{2,5,6}$ The goal of surgery in $\mathrm{NCPH}$ patient is to reduce portal vein resistance by devascularization of esophageal varices and creating a portosystemic shunt. ${ }^{6-8,11,12}$ In NCPH, surgery options can be divided into esophagogastric devascularization, portosystemic shunt, and portoportal shunt (Rex shunt). ${ }^{6,7}$ Various studies have shown shunt patency in $85-98 \%$ patients extrahepatic portal vein obstruction and the long-term survival in $>95 \%$ patients who undergo central splenorenal shunt, mesocaval shunt, portocaval shunt, side-to-side splenorenal shunt, proximal splenorenal shunt, and mesenterico-left portal bypass. ${ }^{5}$

One of the esophagogastric devascularization techniques is Sugiura technique. ${ }^{6,8}$ In 1973, Sugiura and Futagawa showed the method to treat esophageal varices. The Sugiura technique is based on eliminating perforating veins of esophagus and stomach, maintain collaterals which connect the coronary vein to the azygous system. ${ }^{8}$ Original Sugiura technique described with an abdominal and thoracic approach. ${ }^{6}$ Modified Sugiura technique used one stage transabdominal approach to achieve extensive gastroesophageal devascularization. ${ }^{8}$ The first procedure is performed splenectomy. Next step is followed by devascularization of 6-10 $\mathrm{cm}$ of the esophagus. We do transection and end-toend anastomosis of the lower esophagus $4-5 \mathrm{~cm}$ above the gastroesophageal junction with stapling device. After that, we do devascularization of the upper $2 / 3$ of the lesser and 
greater curvatures of the stomach, and pyloroplasty. ${ }^{8}$ Pyloroplasty was performed to facilitate gastric emptying. ${ }^{8}$ Other technique performed left thoracoabdominal approach, preservation of the main trunk of the vagus nerve, highly selective vagotomy, no gastric drainage procedure, and Nissen fundoplication. ${ }^{11}$

Portosystemic shunt (Table 2) can be divided as nonselective (complete portal system decompression to divert all portal flow), selective shunt (variceal-bearing compartment decompression and maintain portal circulation to the liver), and partial (partial portal system decompression and partial portal flow). ${ }^{6}$ About $90 \%$ of patients can be done portosystemic shunt. In long-term studies in Western countries, the outcome of shunt operation with or without splenectomy in children and adults is related to shunt patency $90-95 \%$, rebleeding 5-10\%, no encephalopathy, and 15 year-survival rates $95 \%{ }^{7}$ In young children, portosystemic shunt has a good outcome with low

Table 2 Type of shunt techniques. ${ }^{6,12}$

\begin{tabular}{|c|c|}
\hline \multicolumn{2}{|l|}{ Portosystemic shunts } \\
\hline \multicolumn{2}{|l|}{ Nonselective } \\
\hline $\begin{array}{l}\text { - Portocaval } \\
\text { - Mesocaval } \\
\text { - Proximal } \\
\text { splenorenal }\end{array}$ & $\begin{array}{l}\text { End-to-side or side-to-side anastomosis of } \\
\text { the portal vein and inferior vena cava } \\
\text { Side-to-side or with an interposition graft of } \\
\text { superior mesenteric vein and inferior vena } \\
\text { cava } \\
\text { Requires interposition polytetrafluoroethy- } \\
\text { lene (PTFE) graft of superior mesenteric } \\
\text { vein and right atrium } \\
\text { End-to-side anastomosis of the proximal } \\
\text { splenic vein to left renal vein, involves } \\
\text { splenectomy }\end{array}$ \\
\hline \multicolumn{2}{|l|}{ Selective } \\
\hline $\begin{array}{l}\text { - Warren's distal } \\
\text { splenorenal } \\
\text { - Inokuchi's left gas- } \\
\text { tric venous caval } \\
\text { - Splenocaval }\end{array}$ & $\begin{array}{l}\text { End-to-side anastomosis of the distal splenic } \\
\text { vein and left renal vein, includes ligation of } \\
\text { the left gastric vein and pancreatic veins } \\
\text { End to side anastomosis of the left gastric } \\
\text { vein and inferior vena cava, may require an } \\
\text { autologous graft } \\
\text { End-to-side anastomosis of the distal splenic } \\
\text { vein and inferior vena cava, may need an } \\
\text { interposition PTFE graft }\end{array}$ \\
\hline \multicolumn{2}{|l|}{ Partial } \\
\hline - Sarfeh's portocaval & Uses $8 \mathrm{~mm}$ interposition PTFE graft \\
\hline \multicolumn{2}{|l|}{ Portoportal shunt } \\
\hline - Rex shunt & $\begin{array}{l}\text { Superior mesenteric vein and left portal } \\
\text { system at the Rex recess }\end{array}$ \\
\hline
\end{tabular}

morbidity and mortality (1\%) and low rebleeding rates $(4 \%){ }^{7}$ Surgery in NCPH is better than in cirrhotic patients, with overall 5 years survival approximately $80 \%$, operative mortality $<1 \%$, and shunt patency between $75 \%$ and $100 \%{ }^{6}$ Shunt occlusion can occur if using small diameter synthetic graft or small vein graft. ${ }^{6}$

Surgical technique of conventional Linton's splenorenal shunt (proximal splenorenal shunt) performed left thoracoabdominal approach, but Omar's method performed left subcostal incision. ${ }^{13}$ This approach can extend into the left flank and across midline through rectus muscle. Splenectomy was completed first and identified splenic vein. He dissected the fusion fascia of Toldt from the tail to the middle of the body of the pancreas. Splenic vein was attached to that avascular fascia. It can obtain an optimal length of the splenic vein to anastomosed with left renal vein. ${ }^{13}$

Outcome after surgery for NCPH patient was adequate to prevent rebleeding from esophageal varices, relieve portal gastropathy, portal biliopathy, and decrease portal pressure. ${ }^{6-8,11,13}$ Monitoring the portal pressure can estimate HVPG below $10 \mathrm{mmHg}$, because the weight above it can lead to esophageal and gastric varices, increase collateral of periportal and retroperitoneal, and spontaneous bacterial peritonitis. $^{12}$ The HVPG value of more than 12 $\mathrm{mmHg}$ can lead to rupture and bleeding of the varices. ${ }^{14,15}$

Some study showed endoscopic variceal ligation more effective to prevent variceal rebleeding in the patient with NCPH. ${ }^{16,17}$ But other study showed sclerotherapy could decrease rebleeding $25 \%$ at 2 years and $35 \%$ at 5 years. ${ }^{18,19}$ Mathur et al's study showed that modified Sugiura procedure was effective and safe to prevent longterm variceal rebleeding. They evaluate up to $54 \pm 34$ months, $95 \%$ of patients had no varices. They reported $88 \%$ of the 5-year survival. But the overall complication of this procedure was $4 \%$ mortality post-operation, $15 \%$ esophageal stricture, and $11 \%$ rebleeding. ${ }^{20}$ Goyal et al's study evaluated 45 patients who operated esophagogastric devascularization procedure. It showed overall survival of $35 \%$ in cirrhosis patients and $90.48 \%$ in noncirrhosis patients. The mean followed up was 48 months. ${ }^{21}$

In Japan, if the patient could not undergo shunt surgery, only the devascularization procedure was done. It can be useful option to treat variceal bleeding and prevent rebleeding. ${ }^{12}$ The long-term result of proximal splenorenal shunt had a good result in the patient with extrahepatic portal vein obstruction. It showed $90-95 \%$ shunt patency, $5-10 \%$ rebleeding, 95\% survival until 15 years, and absence of encephalopathy. ${ }^{12,22}$ 
In our case, we performed a modified Sugiura technique and a proximal portosystemic shunt. We performed left subcostal incision like Omar's technique, and then we performed a modified Sugiura technique and proximal splenorenal shunt (Figures 4). We used CDH29A stapling device to do transection and end-to-end anastomosis of the lower esophagus. We observed his condition better after surgery. There was no internal bleeding or OPSI. The patient can do his daily activities and consume propranolol $60 \mathrm{mg}$ per day to prevent portal hypertension. Six months follow-up after surgery, his physical condition was better and no sign of complications.

\section{Conclusion}

NCPH with PVT is a rare condition. Surgery aims to reduce portal vein flow and alter portal vein circulation. Devascularization procedures using modified Sugiura technique are splenectomy; devascularization, transection, and endto-end anastomosis of lower esophagus above the gastroesophageal junction; devascularization of the upper $2 / 3$ of the lesser and greater curvatures of the stomach; and pyloroplasty. This procedure is useful to treat and avoid rupture of esophageal varices. Portal circulation alteration using the proximal splenorenal shunt, which anastomosed end-to-side of the splenic vein to left renal vein. The treatment in NCPH utilizing the combination of modified Sugiura technique and the proximal splenorenal shunt is proper without complication.

\section{Author contributions}

Both authors contributed toward data analysis, drafting and critically revising the paper, gave final approval of the version to be published, and agree to be accountable for all aspects of the work.

\section{Disclosure}

Both of the authors report no conflicts of interest in this work.

\section{References}

1. Sarin SK, Khanna R. Non-cirrhotic portal hypertension. Clin Liver Dis. 2014;18:451-476. doi:10.1016/j.cld.2014.01.009

2. Khanna R, Sarin SK. Non-cirrhotic portal hypertension - diagnosis and management. $J$ Hepatol. 2014;60:421-441. doi:10.1016/j. jhep.2013.08.013

3. Kobilica N, Skalicky M, Milotic F, Flis V. Non-cirrhotic and non-malignant acute extrahepatic Portal Vein Thrombosis (PVT): short- and long-term results. J Int Med Res. 2011;39:1090-1098. doi:10.1177/147323001103900344
4. Seijo S, Plessier A. Noncirrhotic nontumoral portal vein thrombosis. Clinl Liver Dis. 2014;3:118-121. doi:10.1002/cld.336

5. Wani ZA, Bhat RA, Bhadoria AS, Maiwall R. Extrahepatic portal vein obstruction and portal vein thrombosis in special situations: need for a new classification. Saudi J Gastroenterol. 2015;21:129-138. doi:10.4103/1319-3767.157550

6. Marti J, Gunasekaran G, Iyer K, Schwartz M. Surgical management of noncirrhotic portal hypertension. Clinl Liver Dis. 2015;5:112-115. doi:10.1002/cld.470

7. Mangla V, Pal S, Sahni P. Surgery for non-cirrhotic portal hypertension: current status. Trop Gastroenterol. 2016;37:152-155. doi: $10.7869 / \operatorname{tg} .348$

8. Selzner M, Tuttle-Newhall JE, Dahm F, Suhocki P, Clavien PA Current indication of a modified sugiura procedure in the management of variceal bleeding. J Am Coll Surg. 2001;193:166-173. doi:10.1016/s1072-7515(01)00937-1

9. Sahoo AK, Rauta S, Mohapatra SC. Portal vein thrombosis: A rare finding in a noncirrhotic patient. Euroasian J Hepatogastroenterol. 2014;4:55-57. doi:10.5005/jp-journals-10018-1097

10. Turnes J, García-Pagán JC, González M, et al. Portal hypertension-related complications after acute portal vein thrombosis: impact of early anticoagulation. Clin Gastroenterol Hepatol. 2008;6:1412-1417. doi:10.1016/j.cgh.2008.07.031

11. Ginsberg RJ, Waters PF, Zeldin RA, et al. A modified sugiura procedure. Ann Thorac Surg. 1982;34:258-264. doi:10.1016/S0003-4975(10)62494-0

12. Pal S. Current role of surgery in portal hypertension. Indian J Surg. 2012;74:55-66. doi:10.1007/s12262-011-0381-8

13. Shah OJ, Robbani I. A simplified technique of performing splenorenal shunt (Omar's technique). Tex Heart Inst J. 2005;32:549-554.

14. Groszmann RJ, Garcia-Tsao G, Bosch J, et al. Beta blockers to prevent gastroesophageal varices in patients with cirrhosis. $N \mathrm{Engl}$ $J$ Med. 2005;353:2254-2261. doi:10.1056/NEJMoa044456

15. de Franchis R; Baveno V Faculty. Revising consensus in portal hypertension: report of the Baveno $\mathrm{V}$ consensus workshop on methodology of diagnosis and therapy in portal hypertension. J Hepatol. 2010;53:762-768. doi:10.1016/j.jhep.2010.06.004

16. Imperiale TF, Chalasani N. A meta-analysis of endoscopic variceal ligation for primary prophylaxis of esophageal variceal bleeding. Hepatology. 2001;33:802-807. doi:10.1053/jhep.2001.23054

17. Sarin SK, Govil A, Jain AK, et al. Prospective randomized trial of endoscopic sclerotherapy versus variceal band ligation for esophageal varices: influence on gastropathy, gastric varices and variceal recurrence. J Hepatol. 1997;26:826-832. doi:10.1016/s0168-8278(97)80248-6

18. Thomas V, Jose T, Kumar S. Natural history of bleeding after esophageal variceal eradication in patients with extra hepatic portal venous obstruction: a 20 year follow-up. Indian $J$ Gastroenterol. 2009;28:206-211. doi:10.1007/s12664-009-0086-0

19. Bhargava DK, Dasarathy S, Atmakuri SP, Dwivedi M. Comparative efficacy of emergency endoscopic sclerotherapy for active variceal bleeding due to cirrhosis of the liver, non-cirrhotic portal fibrosis and extrahepatic portal venous obstruction. J Gastroenterol Hepatol. 1990;5:432-437. doi:10.1111/j.1440-1746.1990.tb01422.x

20. Mathur SK, Shah SR, Nagral SS, Soonawala ZF. Transabdominal extensive esophagogastric devascularization with gastroesophageal stapling for management of noncirrhotic portal hypertension: long-term results. World J Surg. 1999;23:1168-1174.

21. Goyal N, Singhal D, Gupta S, Soin AS, Nundy S. Transabdominal gastroesophageal devascularization without transection for bleeding varices: results and indicators of prognosis. J Gastroenterol Hepatol. 2007;22:47-50. doi:10.1111/j.1440-1746.2006.04330.x

22. Orloff MJ, Orloff MS, Girard B, Orloff SL. Bleeding esophagogastric varices from extrahepatic portal hypertension: 40 years' experience with portal-systemic shunt. J Am Coll Surg. 2002;194:717-728. doi:10.1016/s1072-7515(02)01170-5 


\section{Publish your work in this journal}

Clinical and Experimental Gastroenterology is an international, peerreviewed, open access, online journal publishing original research, reports, editorials, reviews and commentaries on all aspects of gastroenterology in the clinic and laboratory. This journal is indexed on American Chemical Society's Chemical Abstracts Service (CAS).
The manuscript management system is completely online and includes a very quick and fair peer-review system, which is all easy to use. Visit http://www.dovepress.com/testimonials.php to read real quotes from published authors. 